\title{
Heterogeneity Analysis of the Influence of Capital Going to the Countryside on Rural Household Income
}

\author{
Yu Faying 1,* \\ ${ }^{1}$ School of public Affairs, Chongqing University, Chongqing, 400044, China \\ *Corresponding author. Email: 20180102018t@cqu.edu.cn
}

\begin{abstract}
This paper uses the China Labor Force Survey (CLDS2014) data to empirically analyze the impact of capital going to the countryside on rural household income. The study finds that: capital going to the countryside has significantly increased rural household income as a whole; its impact on rural household income has decreased with increasing household income levels; and the impact of capital going to the countryside on rural household income has heterogeneity among regions. In view of the above conclusions, it is proposed that in the process of promoting capital to the countryside, the land acquisition compensation system should be improved, and the social security mechanism should be improved and appropriate policies and measures should be taken according to the conditions of each region.
\end{abstract}

Keywords: capital to the countryside, rural household income, PSM, Quantile regression

\section{INTRODUCTION}

With the advancement of urbanization, many rural laborers choose to enter the cities to earn a living. The large-scale transfer of labor has caused abandonment of rural land, and agriculture has developed slowly in the absence of human and physical capital. The No. 1 Central Document of 2019 clearly stated that it is necessary to promote rural construction, encourage urban capital to flow to rural areas, and implement the development of rural areas. The income of rural households has always been the focus of attention, and the impact of capital on the countryside has brought attention to farmers. Since the country advocated the process of urbanization, more and more rural land was released, and it is expected that in the future, more rural families will lose land due to capital going to the countryside [1]. In the process of capital going to the countryside, farmers' families are not only concerned about short-term benefits, but also sustainable growth of income [2]. From the existing researches, the impact of capital going to the countryside on rural families is still controversial.

On the one hand, after the capital goes to the countryside, it may cause certain risks to the land-expropriated households. The number of jobs that enterprises can provide is limited, and a large number of land transfers will cause hidden unemployment for rural households [3]. On the other hand, after land requisition, it will help achieve moderate scale operations, significantly increase agricultural productivity of food crops [4].The empirical model of endogenous transformation on the micro data of eight provinces and cities proves that capital going to the countryside can promote the development of rural economy, increase the total household income by $27.3 \%$ and increase the per capita income by $33.3 \%$ [5].
Through combing, it is found that the existing related research still has the following problems. Therefore, based on the data of the Chinese Labor Force Dynamic Survey (CLDS), this article attempts to discuss the impact of capital going to the countryside on rural household income from the perspective of family and regional heterogeneity, and proposes effective measures and suggestions. The innovations of this paper are as follows: First, the impact of capital going to the countryside on rural household income is explored from the perspective of heterogeneity of rural families. The quantile regression method is used to verify the different promotion effects of capital going to the countryside on different households. The method of propensity score matching reduces the deviation caused by the nonrandom behavior of capital going to the countryside. The third is to plan based on different regions and use the Chinese labor force dynamic survey data for large sample regression. The results obtained are more representative.

\section{DATA, VARIABLES AND MODEL}

\subsection{Data sources}

This article selects the access data of the 2014 China Labor Dynamics Survey (CLDS) of Sun Yat-sen University. CLDS collects national labor-related data through regular tracking. The data is tracked every two years. The interview target is rural labor aged 14 to 65 . The access covers a wide range, and the data contains information on the labor force dynamics of all provinces and cities except Hong Kong, Macao, Taiwan, Hainan and Tibet. This article has processed the data accordingly, deleted the erroneous values and unreasonable extreme values, and combined the 
data at the household level and the village level with stata16 for data connection and consolidation.

\subsection{Variable setting}

Explained variable: rural household income. In this paper, the total household income of the interviewees is used as the standard of rural household income.

Core explanatory variable: The core independent variable studied in this article is capital going to the countryside. It is confirmed through reading materials that most of the capital going to the countryside is realized through the transfer of rural land. Therefore, it is defined as whether the village is expropriated by the enterprise or the government.

Control variables: household characteristic variables and village-level characteristic variables. Taking into account the different situations between families, the age, education, health of the family members, the labor force in the family, the area of arable land owned, and whether the farmland is determined as a household-level control variable are considered. The income of rural households is also affected by village-level characteristics, such as the actual living population in the village, the area of agricultural land in the village, whether there is a non-agricultural economy, the main terrain of the village, and the geographical location of the village.

\subsection{Econometric model}

Rural household income is the sum of the income of the family's main labor force, which mainly depends on the family labor force population, age, health and other factors. In addition, rural household income is not only affected by family-level factors, but also related to village infrastructure and environment. Therefore, the equation model based on this is as follows:

income $_{i}{ }^{\text {psm }}=\alpha_{0}+\alpha_{1}$ capital $_{i}+\sum \beta_{i} F_{i}+\sum \gamma_{i} C_{i}+\delta_{i}$

$\mathrm{P}_{\mathrm{i}}$

$+\varepsilon_{\mathrm{i}}$

Among them, income $e_{i}$ represents the logarithm of the total income of the interviewed rural household throughout the year; capital $_{i}$ represents whether village $i$ has capital to go to the countryside; $F_{i}$ and $C_{i}$ represents the

characteristic variables of the household and each village; $\mathrm{P}_{\mathrm{i}}$ represents the dummy variable of the area where the rural households were interviewed; $\varepsilon_{\mathrm{i}}$ is the disturbance term.

\section{RESULTS}

\subsection{Basic Regression Results}

The results in Table 1 confirm that, as a whole, capital going to the countryside has a significant positive impact on rural household income. Model 1 shows that the impact of capital going to the countryside on rural household income positively affects rural household income at the $1 \%$ level in the results without adding control variables. Model 2 and model 3 are based on model 1 and add household and village-level control variables, respectively. Comparing the results of the two, it can be seen that the impact of capital going to the countryside on rural household income is still significant after adding control variables. The coefficients from Model 2 to Model 3 become significantly smaller, indicating that the rural household income will fluctuate to a certain extent due to the influence at the village level. The control variables added at the household level in Model 2. The regression results show that the income of rural households is significantly affected by the age, health status, and education of family members. Families with a large labor force have a significant role in increasing their income. The cultivated land owned by families Area also plays a positive role, but the impact of the confirmation of farmland rights on rural household income is not significant. This may be because households with more arable land can get more compensation, and the confirmation of land tenure is essentially the confirmation of land tenure, and cannot therefore receive more compensation when the capital goes to the countryside or Placement. Model 3 adds factors at the village level. The empirical results show that the area of village agricultural land at the village level, whether the village has a non-agricultural economy (secondary and tertiary industry economy), the terrain of the village, and whether the village is located the suburbs of large and medium-sized cities have a significant impact on rural household income. Because the non-agricultural industries in the village can promote local employment and economic development. In addition, the flatter the village, the more advantages the transferred land can play. Model 4 is the result of adding regional effects, and the core explanatory variable coefficients have changed, reflecting that regional effects have had a certain impact. Detailed analysis of regional differences will be made later. 
Table 1 OLS regression results

\begin{tabular}{lcccc}
\hline & $\begin{array}{c}(\mathbf{1}) \\
\text { Family income }\end{array}$ & $\begin{array}{c}(\mathbf{2}) \\
\text { Family income }\end{array}$ & $\begin{array}{c}(\mathbf{3}) \\
\text { Family income }\end{array}$ & $\begin{array}{c}(\mathbf{4}) \\
\text { Family income }\end{array}$ \\
\hline Capital go to the countryside & $0.411^{* * *}$ & $0.312^{* * *}$ & $0.174^{* * *}$ & $0.184^{* * *}$ \\
& $(0.0274)$ & $(0.0270)$ & $(0.0316)$ & $(0.0314)$ \\
Family control variables & No & Yes & Yes & Yes \\
Village control variables & No & No & Yes & Yes \\
Regional effect & No & No & No & Yes \\
_cons & $9.855^{* * *}$ & $8.729^{* * *}$ & $8.955^{* * *}$ & $9.179^{* * *}$ \\
& $(0.0200)$ & $(0.122)$ & $(0.148)$ & $(0.148)$ \\
\hline N & 7388 & 6374 & 4815 & 4815 \\
R2 & 0.030 & 0.211 & 0.205 & 0.222 \\
\hline
\end{tabular}

\subsection{Quantile Regression Rest on Rural Household Income}

Although this paper has used the average treatment effect (ATT) to measure the net effect of the impact of capital going to the countryside on rural household income, it reflects only the average change in income. Next, we further explore the impact of capital going to the countryside on income at different household income levels. At this stage, quantile regression is used to measure the impact of capital going to the countryside on rural household income at $25 \%, 50 \%, 75 \%$, and $95 \%$ household income levels, respectively. From the regression results in Table 2, we can see that the impact of capital going to the countryside on rural household income gradually decreases with the rise of household income levels. Capital return to the countryside is not significant for rural household income at $95 \%$ income level, and the regression coefficient is the largest for families at $25 \%$ income level. It can be seen that capital to the countryside has the largest income promotion effect on low- and middle-income families. This may be because high-income families are not simply engaged in agricultural production, they are more likely to operate family farms or cooperatives, etc. After the enterprise capital goes to the countryside, it will promote the development of modern technologies and the improvement of village infrastructure, but the transfer of large amounts of land may hinder the expansion of these institutions. Conversely, lower-income households, whether they are hired into enterprises to become new professional farmers or transferred to cities, will generate income growth. Therefore, the effect of capital going to the countryside on rural households with lower incomes is more significant.

Table 2 Quantile regression results

\begin{tabular}{lccccc}
\hline & $\mathbf{( 1 )}$ & $\mathbf{( 2 )}$ & $\mathbf{( 3 )}$ & $\mathbf{( 4 )}$ & $\mathbf{( 5 )}$ \\
& $\mathbf{O L S}$ & $\mathbf{Q R \_ 2 5}$ & $\mathbf{Q R} \mathbf{5}$ & $\mathbf{Q R} \mathbf{7 5}$ & $\mathbf{Q R \_ 9 5}$ \\
\hline Capital go to the & $0.174^{* * *}$ & $0.254^{* * *}$ & $0.173^{* * *}$ & $0.108^{* * * *}$ & 0.0671 \\
countryside & $(0.0316)$ & $(0.0437)$ & $(0.0349)$ & $(0.0326)$ & $(0.0562)$ \\
Family control variables & Yes & Yes & Yes & Yes & Yes \\
Village control variables & Yes & Yes & Yes & Yes & Yes \\
_cons & $8.955^{* * *}$ & $8.431^{* * *}$ & $8.861^{* * *}$ & $9.171^{* * *}$ & $10.25^{* * *}$ \\
& $(0.148)$ & $(0.193)$ & $(0.154)$ & $(0.144)$ & $(0.248)$ \\
\hline$N$ & 4815 & 4815 & 4815 & 4815 & 4815 \\
\hline
\end{tabular}

\subsection{Based on Regional Heterogeneity}

This article divides the sample into three regions: eastern region, central region, and western region. Models 1, 2, and 3 in Table 3 are the results of their respective calculations. It can be seen from the results that capital going to the countryside has obvious regional differences in rural household income. Model 1 shows that capital going to the countryside in the eastern region has a positive effect on rural household income at a significant level of
$1 \%$; Model 2 shows that the impact of capital going to the countryside in the central region on rural household income is not significant; model 3 shows that capital The township has a positive impact on the rural household income in the west at a significant level of $10 \%$. The reason for the above difference may be that due to the characteristics of its economic and geographical environment, in addition to the development of agriculture, forestry, plantation, and other non-agricultural industries are being developed simultaneously in the eastern region, while the western region has a more developed industry than the eastern region. The risks to agricultural production 
itself are relatively high, and there are uncertainties in returns. Therefore, the impact of capital going to the countryside on the eastern region is more significant. The degree of development of the central region lies between the two, and the role of capital going to the countryside to its family income is not significant.

Table 3 Regional heterogeneity

\begin{tabular}{lccc}
\hline & $\begin{array}{c}\text { (1) east } \\
\text { Family income }\end{array}$ & $\begin{array}{c}\text { (2) Central } \\
\text { Family income }\end{array}$ & $\begin{array}{c}\text { (3) west } \\
\text { Family income }\end{array}$ \\
\hline Capital go to the & $0.272^{* * *}$ & 0.0896 & $0.0981^{*}$ \\
countryside & $(0.0546)$ & $(0.0566)$ & $(0.0575)$ \\
Family control variables & Yes & Yes & Yes \\
Village control variables & Yes & Yes & Yes \\
cons & $9.428^{* * *}$ & $8.662^{* * *}$ & $8.619^{* * *}$ \\
& $(0.240)$ & $(0.276)$ & $(0.257)$ \\
\hline Observations & 1935 & 1405 & 1475 \\
R2 & 0.207 & 0.227 & 0.158 \\
\hline
\end{tabular}

\section{CONCLUSIONSAND RECOMMENDATION}

Based on the data from the Chinese Labor Force Dynamics Survey (CLDS) to explore the impact of capital going to the countryside on rural household income, the following conclusions are drawn: First, the impact of capital going to the countryside on rural household income as a whole is positive and significant, but the OLS model underestimates the size of the influence coefficient. Second, the average age of family labor force members has a negative impact on rural household income; rural household income is positively affected by the level of family education, health, and labor force. Third, rural household income is also affected by non-agricultural economy and village topography at the village level, which shows that the village economy and village infrastructure conditions have a certain effect on rural household income. Fourth, empirical evidence based on the quantile regression method shows that the impact of capital going to the countryside on rural household income decreases with rising income levels. Fifth, the return of the eastern, central, and western regions respectively shows that the impact of capital going to the countryside on rural household income is more significant in the eastern region than in the western region, but not significant in the central region.

Suggestions based on the above conclusions: First, improve the corresponding compensation system. Protecting the rights and interests of land-expropriated subjects can obtain reasonable and fair compensation according to law. Second, improve the corresponding social security mechanism and promote pluralistic resettlement. The government should consider the sustainable growth of farmers' income after the capital goes to the countryside, and implement different resettlement measures according to the characteristics of different families and different regions. For example, for families with relatively backward regions, older family labor and poor non-agricultural employability, more monetary subsidies or social security policies such as medical care, education, and old-age care should be provided; and for more developed regions such as the east, families with high quality and strong non-agricultural employment ability provide more long-term employment resettlement. Third, compensation targets are treated differently, and protection for low-income groups is strengthened. In the process of land requisition, special attention should be paid to those whose land is in poor physical condition and low education level. Because it is difficult to complete employment transformation in the short term, the protection of these vulnerable groups should be strengthened, and they should formulate corresponding protection policy for their respective situations.

\section{REFERENCES}

[1] Bao H, Peng Y. Effect of land expropriation on land-lost farmers' entrepreneurial action: A case study of Zhejiang Province[J]. Habitat International, 2016,53.

[2] Wang Xiansheng, Guo Zhongxing, Li Ning, et al. Impact of Land Acquisition on Farmers' Employment and Welfare-An Empirical Analysis Based on CHIP Data [J]. Journal of Public Management, 2019,16(01):153-168.

[3] Chenxi L, Zenglei X. Social Stability Risk Assessment of Land Expropriation: Lessons from the Chinese Case.[J]. International journal of environmental research and public health, 2019,16(20).

[4] Liu Wei, Zhang Yingliang, Li Guozhen, et al. Industrial and commercial capital going to the countryside, factor allocation and agricultural production efficiency [J]. Agricultural Technology and Economy, 2018(09):4-19.

[5] Shi Changliang, Luan Jiang, Zhu Junfeng, et al. Impact of Land Circulation on Farmers' Income Growth and Income Gap_Empirical Analysis Based on Survey Data of Farmers in 8 Provinces [J]., 2017(05):152-16. 